\title{
Factors affecting attitude of medical students to pursue surgical career
}

\author{
Ghimire R', Regmi S², Bhattarai S ${ }^{3}$
}

${ }^{1}$ Roshan Ghimire, Lecturer; ${ }^{2}$ Sujan Regmi, Resident; ${ }^{3}$ Sandeep Bhattarai, Intern; Department of General Surgery, Kathmandu Medical College Teaching Hospital, Kathmandu, Nepal

\begin{abstract}
Background: Medical students are always in a dilemma for their career choice after under-graduation as there are multiple options and none of the choices come without any drawbacks. Multiple factors determine their preferences. Objective: This study aimed to identify the factors that determine career choice and to discuss how it affects the students in taking surgery as their career.

Methods: A questionnaire was developed which included factors that encourage and also influence students to consider surgery as their career. A cross-sectional study was conducted among 292 participants and they were divided into two groups, preclinical and clinical students. The collected data was tabulated and analyzed using Statistical Package for Social Sciences version 20.

Results: Out of the 292 students, 144 (49.32\%) were males and 148 (50.68\%) were females. Of the total, 233 (79.8\%) students thought of choosing surgery as their career while 41 (14.04\%) of the students disagreed for choosing surgery. Among the 233 students, 76 (32.6\%) were from preclinical and 157 (67.38\%) were clinical students. Better earning and role model influenced them to take surgery as their career whereas lack of private life and great dedication were the deterrent factors.

Conclusion: There are various factors that affect students' preference in opting for surgical career. Even though this study reveals many factors contributing towards one's interest in surgical field, it was not statistically significant, and hence, the conclusive results could not be drawn.
\end{abstract}

Key words: Attitude, Medical student, Surgical career

\section{INTRODUCTION}

$\mathrm{D}$ ifferent institutions under affiliation of Kathmandu University and Tribhuvan University, BP Koirala Institute of Health Sciences (BPKIHS) and Patan Academy of Health Sciences (PAHS) in Nepal are conducting a course for Bachelors in Medicine and Bachelors in Surgery (MBBS). More than one thousand students graduate each year in Nepal' ${ }^{1}$. During MBBS, students form opinion on their future career. However, hard work and to some extent fate, luck and other factors decide whether they finally get to study what they desire. Nonetheless, some simply go with what time has for them.

Many have studied MBBS in Nepal, simply because this field has scope in today's time. After completing

Address for correspondence

Dr. Roshan Ghimire

Lecturer, Department of Surgery

Kathmandu Medical College Teaching Hospital

Sinamangal, Kathmandu, Nepal

E-mail: roshanghimire@mail.com intermediate, $10+2$ or A levels, students choose medicine as their career. Only few MBBS graduate can decide their field of interest by the time they graduate. The factors that play a key role for the students in deciding their future career needs to be studied.

In clinical sciences, Medicine, Surgery, Pediatrics, Obstetrics and Gynecology are considered as the major subjects. Students have rotational posting in these departments and its allied-departments such as psychiatry, dermatology, anesthesia, dental surgery, radiology, and orthopedics. They are also posted in other specialties like community medicine, forensic medicine, ophthalmology and otorhinolaryngology. The medical students often decide on their interest of study in clinical science by virtue of the experience gained during their clinical postings. Medical history taking, performing clinical examinations, bedside teaching and tutorials trigger their interest in the respective fields. 
Family insistence, peer pressure and the parents themselves being a specialist in a particular field might be some other factors that guide them to pursue a career in that field. Assessment of quality of life in future also determines the career they choose ${ }^{2}$. In our study we assessed effect of these factors in developing attitude of students towards career in surgery in the context of our country.

\section{METHODS}

A cross-sectional study, structured questionnaire based study was conducted amongst the MBBS students of Kathmandu Medical College (KMC). Pre-clinical students (fifth semester students) had no clinical exposure as they just completed basic science of two years duration and clinical students (ninth semester students) had clinical exposure of two years. All the enrolled students in a batch in these two groups were identified as study group. Ethical clearance was obtained from institutional review board for performing the study. One intern student was present during questionnaire and sample collection. All the procedures were well explained to the study group with their consent. Confidentiality was given the utmost importance.

A graded questionnaire was developed and the response of the students was collected. The questionnaire included whether the students wanted to pursue surgery as their career or not, and the factors influencing them in deciding for or against it. In the questionnaire, the students were initially asked whether they have considered taking surgery as their career at least once or not.

The respondents were kept anonymous to prevent any kind of bias. The lectures and demonstration of anatomy and the effect of problem based learning (PBL) classes were assessed to see if those persuaded them in choosing surgery as their career. Similarly, the bedside surgical case demonstration, attitude and work ethics of surgeons and looking up to some surgeons as their role model were the other factors that were assessed. The students were also asked whether the prospects of having a good reputation, financial benefits or a better life style encouraged them in pursuing a surgical career or not. Statistical Package for Social Sciences version 20 was used to analyze the data. Chi square test was used.

\section{RESULTS}

The total number of students enrolled in the study was 292. There were 112 pre-clinical students and 180 clinical students. There were 144 (49.32\%) male and 148 (50.68\%) female participants. Mean age of participant was 22.07 years with standard deviation (SD) of 1.73.

Altogether, 233 (79.8\%) students thought of taking surgical career (Table 1 ).

Among male (144) participants, 73 (50.68\%) opted surgery and among female participants (148), 73 $(49.32 \%)$ thought of choosing surgery as their career.

Among the participants who thought of taking surgery as their career (233), 76 (32.62\%) belonged to preclinical and $157(67.38 \%)$ to clinical group.

Most of the participants thought better earning and influence of their role model are the prime factors for choosing surgery as their career (Table 2).

Among 126, 48 (38.1\%) who agreed for better earning were preclinical and 78 (61.9\%) were clinical students. Out of 161 , who chose surgery because of role model, 34 (21.1\%) were preclinical and 127 (78.9\%) were clinical students.

Great dedication and lack of private life were the discouraging factors to pursue surgical career among students. (Table 3)

Among 32 students who disagreed for pursuing surgical career because of need of great dedication, 8 (25\%) were from preclinical and 24 (75\%) were from clinical students. Among 34 students who thought of lack of private life in surgical field, 11 (32.35\%) were from preclinical and 23 (67.64\%) were from clinical students.

There was no gender difference noted on choosing surgery as their career (Table 4). 
Table 1: Percentage of student who thought of taking surgery as their career

\begin{tabular}{ccc}
\hline Thought of taking surgical career? & Frequency & Percent \\
Yes & 233 & 79.8 \\
No & 41 & 14.04 \\
\hline Don't know & 18 & 6.16 \\
\hline
\end{tabular}

Table 2: Factors that influenced participants to pursue their career as surgeons $(\mathbf{n}=\mathbf{2 3 3})$

\begin{tabular}{lcccccc}
\hline \multirow{2}{*}{ Factors } & \multicolumn{2}{c}{ Agreed } & \multicolumn{2}{c}{ Disagreed } & \multicolumn{2}{c}{ Don't know } \\
& Frequency & Percent & Frequency & Percent & Frequency & Percent \\
Better earning & 126 & 54.07 & 36 & 15.45 & 79 & 33.9 \\
Influence of role model & 161 & 69.09 & 20 & 8.58 & 52 & 22.3 \\
\hline
\end{tabular}

Table 3: Factors that discouraged participants to pursue their career as surgeons $(\mathbf{n}=\mathbf{4 1})$

\begin{tabular}{lcccccc}
\hline & \multicolumn{2}{c}{ Agreed } & \multicolumn{2}{c}{ Disagreed } & \multicolumn{2}{c}{ Don't know } \\
\cline { 2 - 4 } & Frequency & Percent & Frequency & Percent & Frequency & Percent \\
Great dedication & 32 & 78.04 & 7 & 17.07 & 2 & 4.87 \\
Lack of private life & 34 & 82.92 & 6 & 14.64 & 1 & 2.44
\end{tabular}

Table 4: Percentage of male and female participants from preclinical and clinical who were determined to be Surgeons $(\mathbf{n}=\mathbf{2 3 3})$

\begin{tabular}{ccccc}
\hline \multirow{2}{*}{ Sex } & \multicolumn{2}{c}{ Preclinical (76) } & \multicolumn{2}{c}{ Clinical (157) } \\
& Frequency & Percent & Frequency & Percent \\
Male & 37 & 48.68 & 79 & 50.31 \\
Female & 39 & 51.31 & 78 & 49.68 \\
\hline
\end{tabular}

\section{DISCUSSION}

Medicine is considered as a noble profession all over the world and our country is not an exception. Amongst the various specialties in medicine itself, surgery is considered a charismatic one. Though in United Kingdom, United States of America and Canada, number of applicants choosing for surgery is declining ${ }^{3,4}$. But the choice of surgery as a career is not unanimous. Students' mindset can be influenced with various factors while considering a particular specialty as their lifelong career. Our study also shows that various factors such as role model, better earning, dedication towards the field and impact of work on private life has influence on choosing surgery as a career.

In this study, only $14.04 \%$ of total students said that they have never thought of taking surgery as their profession and there was no significant difference between the two genders that agreed for pursuing surgery.

The reason why no significant difference was seen between the two sexes could be due to the changing trend of preference amongst students. Whereas it could also be reasoned that our study population was not mature enough to decide a career for themselves and they were not properly aware of the implication of taking surgery as their profession. Women perceive surgical career as hard and inflexible according to a study done by Wendel $\mathrm{TM}^{5}$. Not finding a difference between the two genders on choosing surgery as their career in our study can be considered as an interesting fact.

Cultural and work environment are considered a deterrent factor even in developed countries ${ }^{6}$. Long working hours and greater level of dedication that the field requires lures less number of females towards the specialty ${ }^{7,8,9,10}$. Our study also shows that greater level of dedication in the surgical field $(78.1 \%)$ and lack of private life (82.92\%) were deterrent factors for pursuing surgical career.

A role model is usually necessary for any individual to pursue and to get inspired to choose a particular field as their career ${ }^{6,11}$. An article published in the World Journal of Surgery by Ravindra P, 63\% of the participants said they felt they were able to identify a surgical role model 
with a significant difference between identification of a surgical role model and interest in pursuing surgical careers $^{12}$.

In our study, among students pursuing surgical career, 161 (69.09\%) chose surgery because of a particular role model as their inspiration. It would be highly relevant to say that our department has such personalities who students look up to and thereby inspired by them to choose surgical field.

126 (54.67\%) believed that they would have a financially stable life if they take surgery as a career. A compromised family life is seen as one of the most deterrent factor even in the more developed western countries and it accounts for one of the most important factor why the

\section{REFERENCES}

1. Dixit $\mathrm{H}$, Marhatta SB. Medical education and training in Nepal: SWOT analysis. Kathmandu University Medical Journal. 2008 Jul-Sep;6(23):412-20.

2. Brundage SI, Lucci A, Miller CC, Azizzadeh A, Spain DA, Kozar RA. Potential targets to encourage a surgical career.Journal of the American College of Surgeons.2005;200:946-53.

3. Podnos Y, Cambell B, Wilson S. Patterns of graduating medical student career selections from 1993 to 1998 and their effect on surgery as a career choice. Archives of Surgery.1999; 134:876-81.

4. Marschall JG, Karimuddin AA. Decline in popularity of general surgery as a career choice in North America: Review of postgraduate residency training selection in Canada, 1996-2001. World Journal of Surgery.2003 Mar;27(3):249-52.

5. Wendel TM, Godellas CV, Prinz RA. Are there gender differences in choosing a surgical career? Surgery. 20030ct;134(4):591-96.

6. Rogers ME, Creed PA, Searle J. What junior doctors think about choosing a surgical career?AustralianHealth Review. 2012;36(2):191-96.

7. Dorsey ER, Jarjoura D, Rutecki GW. The influence of controllable lifestyle and sex on the specialty choices students mostly females don't want to take up surgery as a career. In a study done at Australia, students said that they would even consider a career change to achieve a work family balance ${ }^{13}$. In our study great dedication and lack of private life were the discouraging factors for deciding surgical career.

\section{CONCLUSION}

From this study we can say that there are various factors that seem to affect the student's preference in deciding their career. There was no significant difference between the two genders when the students were asked about their career preference. But since these factors were not statistically significant a conclusive result could not be found. So a more extensive survey and a larger study group are required to analyze these factors properly.

of graduating U.S. medical students, 1996-2003. Academic Medicine. 2005 Sep;80(9):791-96.

8. Creed PA, Searle J, Rogers ME. Medical specialty prestige and lifestyle preferences for medical students. Social Science \& Medicine.2010 Sep;71(6):1084-88.

9. Evans J, Goldacre MJ, Lambert TW. Views of UK medical graduates about flexible and part-time working in medicine: A qualitative study. Medical Education. 2000 May;34(5):355-62.

10. Gargiulo DA, Hyma NH, Hebert JC. Women in surgery: do we really understand the deterrents? Archives of Surgery.2006 Apr;141(4):405-08.

11. Tammy D, Allen, Lillian T. Eby. Factors related to mentor reports of mentoring functions provided: Gender and relational characteristics. Sex Roles. 2004;50:129-39.

12. Ravindra $P$, Fitzgerald JE. Defining surgical role models and their influence on career choice. World J Surg. 2011 Apr;35(4):704-09.

13. Tolhurst HM, Stewart SM. Balancing work, family and other lifestyle aspects: a qualitative study of Australian medical students attitudes. Med J Aust. 2004 Oct;181(7):361-64. 